\title{
Water Footprint Assessment of Food Loss and Waste Management Strategies in Spanish Regions
}

\author{
Daniel Hoehn ${ }^{1}$, María Margallo ${ }^{1}$, Jara Laso ${ }^{1}$, Israel Ruiz-Salmón ${ }^{1}$, Ana Fernández-Ríos ${ }^{1}$, Cristina Campos ${ }^{1}$, \\ Ian Vázquez-Rowe ${ }^{2}$, Rubén Aldaco ${ }^{1, *(D)}$ and Paula Quinteiro ${ }^{3}{ }^{(D)}$
}

1 Department of Chemical and Biomolecular Engineering, University of Cantabria, 39005 Santander, Spain; daniel.hoehn@unican.es (D.H.); maria.margallo@unican.es (M.M.); jara.laso@unican.es (J.L.); israel.ruizsalmon@unican.es (I.R.-S.); ana.fdezrios@unican.es (A.F.-R.); cristina.campos@unican.es (C.C.)

2 Peruvian LCA Network (PELCAN), Department of Engineering, Pontificia Universidad Católica del Perú, Lima 15088, Peru; ian.vazquez@pucp.pe

3 Centre for Environmental and Marine Studies (CESAM), Department of Environment and Planning, Campus Universitario de Santiago, University of Aveiro, 3810-193 Aveiro, Portugal; p.sofia@ua.pt

* Correspondence: aldacor@unican.es

check for updates

Citation: Hoehn, D.; Margallo, M.; Laso, J.; Ruiz-Salmón, I.;

Fernández-Ríos, A.; Campos, C.;

Vázquez-Rowe, I.; Aldaco, R.

Quinteiro, P. Water Footprint

Assessment of Food Loss and Waste Management Strategies in Spanish

Regions. Sustainability 2021, 13, 7538. https://doi.org/10.3390/su13147538

Academic Editor: Silvia Fiore

Received: 14 May 2021

Accepted: 1 July 2021

Published: 6 July 2021

Publisher's Note: MDPI stays neutral with regard to jurisdictional claims in published maps and institutional affiliations.

Copyright: (C) 2021 by the authors Licensee MDPI, Basel, Switzerland This article is an open access article distributed under the terms and conditions of the Creative Commons Attribution (CC BY) license (https:// creativecommons.org/licenses/by/ $4.0 /)$

\begin{abstract}
The availability of freshwater is one of the biggest limitations and challenges of food production, as freshwater is an increasingly scarce and overexploited resource in many parts of the world. Therefore, the concept of water footprint (WF) has gained increasing interest, in the same way that the generation of food loss and waste (FLW) in food production and consumption has become a social and political concern. Along this line, the number of studies on the WF of the food production sector is currently increasing all over the world, analyzing water scarcity and water degradation as a single WF indicator or as a so-called WF profile. In Spain, there is no study assessing the influence of FLW generation along the whole food supply chain nor is there a study assessing the different FLW management options regarding the food supply chain's WF. This study aimed to assess the spatially differentiated WF profile for 17 Spanish regions over time, analyzing the potential linkages of FLW management and water scarcity and water degradation. The assessment considered compliance and non-compliance with the Paris Agreement targets and was based on the life cycle assessment approach. Results are highlighted in a compliance framework; the scenarios found that anaerobic digestion and aerobic composting (to a lesser extent) had the lowest burdens, while scenarios with thermal treatment had the highest impact. Additionally, the regions in the north of Spain and the islands were less influenced by the type of FLW management and by compliance with the Paris Agreement targets.
\end{abstract}

Keywords: water footprint; water profile; water scarcity; water degradation; food waste; Spain

\section{Introduction}

The availability of freshwater is one of the biggest limitations and challenges of food production, as freshwater is an increasingly scarce and overexploited resource in many parts of the world [1]. Moreover, freshwater and food access are far from being guaranteed for a substantial part of the world's population [2]. Assuming that freshwater is a limited resource, the concept of water footprint (WF) has gained increasing interest in recent years [3]. As described by Quinteiro et al. [4], this concept was first proposed by the quantification of virtual water flows between nations in relation to the international crop trade, presented by Hoekstra and Hung [5]. Subsequently, it was described in greater detail in the WF calculation for each nation worldwide presented by Chapagain and Hoekstra [6], in the worldwide WF of cotton consumption developed by Chapagain et al. [7], and in the WF assessment manual created by Hoekstra et al. [8]. This WF method quantifies both direct and indirect volumetric freshwater use and pollution along supply chains, looking not only at the direct water use of a consumer or producer, but also at the indirect water 
use [9]. According to Hoekstra et al. [8], the WF of a product comprises three color-coded components: green water (i.e., rainwater evapotranspirated from soil moisture), blue water (i.e., fresh surface and groundwater-water in rivers, lakes and aquifers), and grey water (i.e., water quality impairment).

More recently, a novel WF assessment framework was developed and summarized in the ISO 14,046 [10] in order to assess both quantitative and qualitative water-related impacts from a life cycle perspective and encompassing freshwater scarcity (water consumption) and water quality degradation. Following ISO recommendations, in order to overcome the lack of a consensual assessment method related to the most critical and controversial pillar of WF-quantifying water scarcity - and following the recommendation of the UNEP/SETAC Life Cycle Initiative, the Available Water Remaining (AWARE) method has arisen [11]. It has been the first assessment method destined at estimating the impact of the removal of a certain quantity of blue freshwater from its natural systems, i.e., the relative availability of water remaining per area in a watershed, after the demands of humans and aquatic ecosystems have been met [12]. The life cycle assessment (LCA)-based WF impact methodology has progressed rapidly, the WF of a product being the sum of all the water consumed across its entire value chain [13]. It is composed of a set of methods for addressing different freshwater types and sources, pathways, and characterization models with different spatial and temporal scales [14].

Food and in particular agri-food products have a great demand for water [14], the sector being increasingly analyzed by many WF studies globally [15]. In this sense, in 2020, Mekonnen and Gebens-Leenes [16] highlighted the fact that global studies that estimated the global (green plus blue) WF of crop production range from 5938 to $8508 \mathrm{~km}^{3} /$ year. They explained that the existing differences in the WF estimated in the literature can be assumed to be due to differences in the modeling approach, input data, including climate and cultivated area, the number of crops and their specification, and the methods used. As presented by Quinteiro et al. [4], different methods have been developed to assess the impacts related to freshwater as an integral part of the LCA methodology, which have also been applied to a wired range of agricultural and agro-industrial products such as pasta sauce and peanuts [17], broccoli [18], asparagus and tomato [19], among others. Due to the relatively recent development of these methods, the LCA community has been recommending their application in case studies of food products in order to understand the individual significance of each one [20]. For instance, the worldwide average WF has been estimated as $40 \mathrm{l}$ per slice of bread, 741 per $250 \mathrm{~mL}$ of beer, $2497 \mathrm{l}$ per $\mathrm{kg}$ of rice, and $3178 \mathrm{l}$ per kg of hard cheese [21]. More specifically, Karandish et al. [22] studied the green, blue, and grey WF associated with the production of wheat, barley, and rice, and the resulting water scarcity and pollution levels at the provincial scale in Iran. The results suggested that the total WF has increased considerably since 1980.

In this context, Spain is one of the main producers of agricultural products, in spite of being the most arid country of the European Union (EU), becoming an important exporter to other nations. Consequently, the management of water resources in Spain is an important and controversial issue [9]. According to Chapagain and Hoekstra (2004) [6], total water requirements in Spain (green and blue) by the different economic sectors are about $100 \mathrm{~km}^{3} /$ year, $80 \%$ of which can be directly attributed to the agricultural sector. Different studies have already analyzed the WF within different topics in the field of the food supply chain (FSC) in Spain. Among them, López-Gunn et al. (2012) [23] addressed the WF linked to shifts from recommended diets. In 2014, Duarte et al. [24] studied the evolution of domestic water consumption as a consequence of increasing agricultural production, as well as the impact that the increasing need for water had on the construction of infrastructure for irrigation, examining the water consumed in the production of vegetable and animal goods between 1860 and 2010. In 2018, Villanueva-Rey et al. [25] analyzed the WF profile of grapes used in the vinification process in the Ribeiro appellation for the period 2000-2009. In that same year, water entanglement within and beyond Spain was assessed by Blas 
et al. [13], who focused on the study of food consumption and waste generation in Spanish households, grouping total food into 10 different groups.

In this framework, when food is wasted, embedded water and energy used to grow and process crops and other food products are also wasted. Moreover, greenhouse gas emissions are emitted, and a wide range of other environmental impacts (e.g., toxicityrelated impacts, eutrophication, etc.) are generated. The quantification of water and other environmental impacts of food and drink waste is of great potential interest, and WF is a useful tool for linking water resource use to food production [26]. In this regard, food loss and waste (FLW) have turned into one of the main social and political issues of concern, since more than a third of the food production worldwide is wasted along the food supply chain (FSC), reaching a FLW of $20 \%$ of the total production in the EU [27].

A few studies have already studied the WF of FLW generation in some stages of the FSC in certain countries, as is the case of the work developed by Zero Waste Scotland [28], which estimated that the WF of avoidable food waste represented nearly $6 \%$ of all of Scotland's water requirements. Ridoutt et al. [1] assessed the WF of FLW of fresh mango in Australia, suggesting that interventions to reduce FLW will have an important impact in terms of freshwater resource availability. Currently, just a small portion of the FLW generated in Spain is managed in thermal treatment plants or put down to aerobic composting (AC) or anaerobic digestion (AD) systems in mechanical-biological plants, whereas most of the FLW is still sent to landfills [29].

Along this line, although certain studies have already assessed WF impacts regarding some stages or products of the FSC, as far as we were able to ascertain, there is no study assessing the influence of FLW generation along the whole FSC or along the different FLW management options regarding its WF. As previously highlighted, the most environmentally friendly management options for each region of Spain varies significantly [30]. This study aimed to include a WF LCA-based approach to the decision-making process on FLW management in Spain regarding the 17 regions. In a 2015-2040 period, two frameworks were considered: (i) compliance (2DS), and (ii) non-compliance (Business as Usual or BAU) with the Paris Agreement targets, which aim to keep global warming below $2{ }^{\circ} \mathrm{C}$ and pursue efforts limiting it to $1.5^{\circ} \mathrm{C}$. Thereby, the quantification of water and different environmental footprints in the regions of Spain [30] would be linked. This strategy has been suggested by previous studies, as food and drink waste are of great potential interest to a range of stakeholders such as consumers, food retailers, suppliers and producers, NGOs, environmental agencies, water management policy groups, and national and regional governments [28]. The benefits of this perspective aim to complete and reinforce the thesis of the need for developing regionalized FLW management policies in Spain, moving from national to regional approaches when developing future roadmaps.

\section{Methods}

\subsection{Goal, Function, and Functional Unit Definition}

This study conducted a WF assessment based on the ISO 14,046 [10] and is linked to a previous study that developed an LCA methodology regarding other environmental impacts [30], aiming to determine the best scenario of FLW management for the 17 Spanish regions (see description in Figure 1). For this purpose, a comparison of the current FLW management in each region (scenario S1) and other five alternative options (S2-S6) was carried out, simulating different potential situations (as explained below, in Section 2.3). The performance of these scenarios was assessed from an environmental perspective from 2015 until 2040 considering the two frameworks previously mentioned (2DS and BAU). 


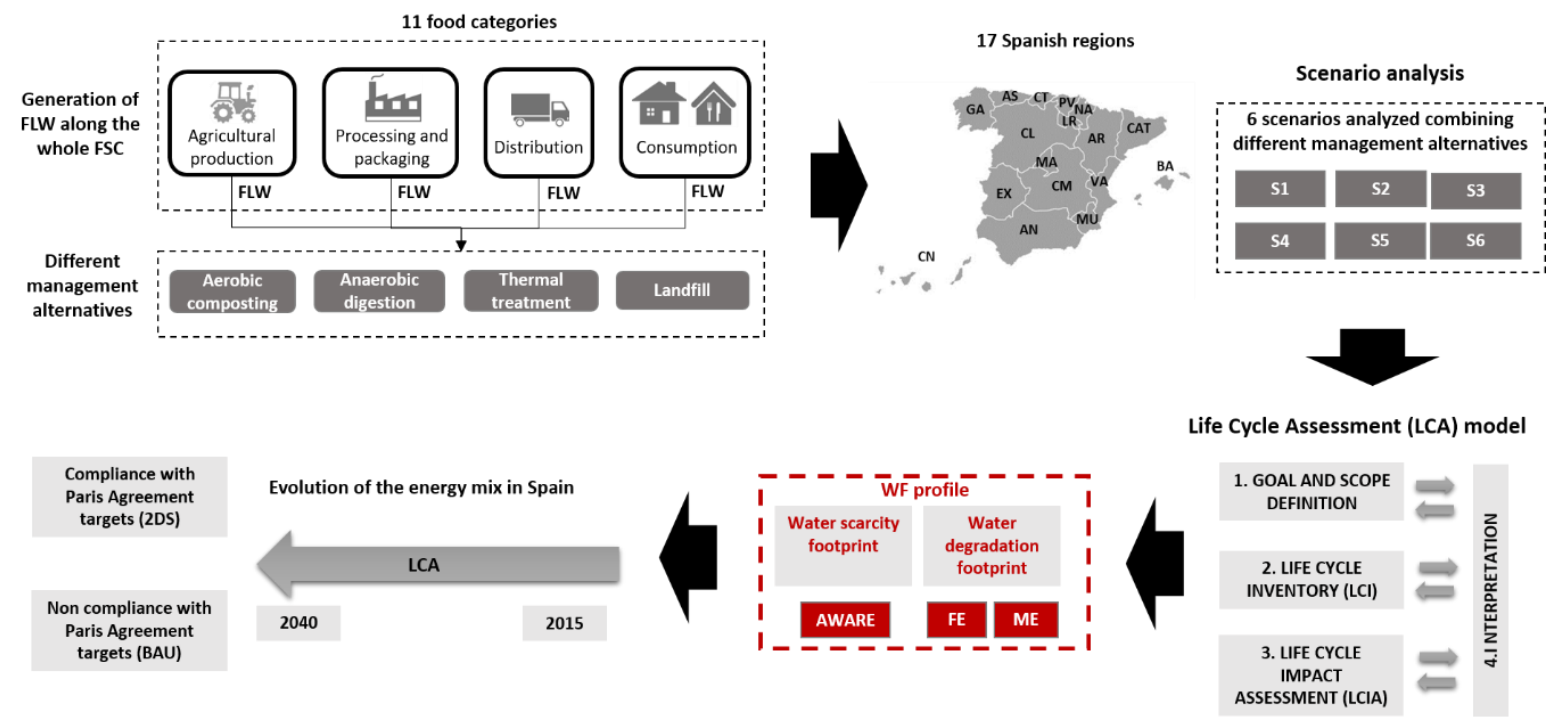

Figure 1. Graphical chart of the LCA methodology and the WF assessment (in red). Regions: AN: Andalusia, AR: Aragon, AS: Principality of Asturias, BA: Balearic Islands, CAT: Catalonia, CL: Castile and Leon, CM: Castile-La Mancha, CN: Canary Islands, CT: Cantabria, EX: Extremadura, GA: Galicia, LR: La Rioja, MA: Community of Madrid, MU: Region of Murcia, NA: Chartered Community of Navarra, PV: Basque Country, VA: Valencian Community, FE: Freshwater eutrophication. ME: Marine eutrophication.

In order to develop the simulations over time, the energy mix projections developed by the TIMES Integrated Assessment Model from the University College London (TIAMUCL) was used. For this assessment, given that Spain was considered as a case study, data for Western Europe were used among those available in the model (16 regions) [31]. The energy used and generated for the energy mix are linked to environmental impacts and avoided burdens, respectively. The scope includes the definition of the function and functional unit (FU). In light of the main function of the system being to manage FLW under different simulated scenarios, an appropriate functional unit to accomplish this function is one metric ton of FLW treated in each region of Spain in 2015.

\subsection{System Boundaries}

As Figure 1 illustrates, the system boundaries include food loss, which is generated in agricultural production, processing, and packaging, i.e., the first stages of the FSC, and food waste that is produced in the last stages, i.e., distribution and consumption, in addition to the FLW management [30]. FLW has been separated into 11 fractions, following the division suggested by FAOSTAT [32], considering different food categories-namely, sweets, cereals, vegetables and vegetable oils, pulses, fruits, roots, eggs, dairy products, fish and seafood, and meat. Similar WF loads of FLW collection and transportation were assumed for all management options due to their low influence, and therefore they were not included in the system boundaries. The mass balances from Garcia-Herrero et al. [33] were used, and the calculated FLW management percentages were those shown in Hoehn et al. [30]. Due to their low demographic weight $(<0.4 \%)$, the autonomous cities of Ceuta and Melilla were discarded from the study.

\subsection{Description of Scenarios under Study}

Six scenarios were evaluated in the WF assessment based on their implementation in the 17 Spanish regions. Scenario 1 (S1) constitutes the baseline scenario, considering the FLW management in each region in 2015 (year of reference), according to the data reported by the CONAMA Foundation [34] and the Spanish Waste Management Framework Plan [29]. Scenario 2 (S2) is based on the FLW framework in Germany, with AC accounting for most of the treatment $(75 \%)$ and AD systems increasingly promoted $(20 \%)$ [35]. The remaining fraction is landfilled $(2.5 \%)$ and subjected to thermal treatments $(2.5 \%)$. In sce- 
nario 3 (S3), the percentage of FLW directed to AD and AC is the contrary of S2, i.e., 75\% is managed by AD, whereas $20 \%$ goes to AC. As in S2, the rest is distributed between landfilling $(2.5 \%)$ and thermal treatment (2.5\%). Scenario 4 (S4) establishes that $90 \%$ of biowaste is incinerated, i.e., it goes to thermal treatment, according to Danish conditions [36], whereas the remaining FLW is divided between landfill, AD, and AC. Scenario 5 (S5) stands up for the promotion of FLW as a valuable source that should never be landfilled [37]. Hence, it considers that the waste is equally distributed and managed by the other three potential alternatives (33.3\% to incineration, $33.3 \%$ to $\mathrm{AC}$, and $33.3 \%$ to AD). Finally, the definition of scenario 6 (S6) only takes into account AD and AC, directing half of the FLW to each treatment. The fact of excluding thermal treatment plants in S6 refers to the fact, that similar to what has recently occurred to coal plants in many nations including Spain, they will potentially have problems providing energy to the system by the year 2030. More specifically, they will have serious difficulties maintaining competitiveness against other technologies in an environment highly conditioned by the European response to climate change, in which the cost of $\mathrm{CO}_{2}$ will tend to be increasingly higher [38]. The simulations (S2-S6) described above are summarized in Table 1. On the other hand, Table 2 shows the assumed distribution of treatment of FLW in all the Spanish regions (S1). The fact that in the regions of Castile La Mancha (CM), Extremadura (EX), and the Region of Murcia (MU) $100 \%$ of the FLW goes to landfill is remarkable. In the region of Andalusia (AN), $93.8 \%$ is landfilled. On the other hand, in Balearic Islands (BA) and Cantabria (CT), a higher fraction goes to thermal treatment plants $(72.7 \%$ and $64.9 \%$, respectively).

Table 1. Simulated scenarios of FLW management. Scenarios S2 to S6 follow the Directive 1999/31/EC on waste landfilling [39].

\begin{tabular}{ccccc}
\hline Scenarios & AD & AC & Landfill & Thermal Treatment \\
\hline S1 & \multicolumn{5}{c}{ Depending on each region (see Table 2) } \\
S2 & $20.0 \%$ & $75.0 \%$ & $2.5 \%$ & $2.5 \%$ \\
S3 & $75.0 \%$ & $20.0 \%$ & $2.5 \%$ & $2.5 \%$ \\
S4 & $3.3 \%$ & $3.3 \%$ & $3.3 \%$ & $90.0 \%$ \\
S5 & $33.3 \%$ & $33.3 \%$ & & $33.3 \%$ \\
S6 & $50.0 \%$ & $50.0 \%$ & \\
\hline
\end{tabular}

\subsection{Life Cycle Model}

The life cycle model described in Figure 2, based on Hoehn et al. [30], includes the generation of FLW in all the considered FSC stages: agricultural production, processing and packaging, distribution and consumption. The management of these FLW was modelled based on the Ecoinvent database [40] and the professional database of GaBi [41]. The input and output water flows of the unit processes were modified in order to consider the regionalized water consumptive use in Spain. FLW management considers the alternatives of AC, AD, thermal treatment, and landfill:

- The modeling of the AC system was developed using the professional database of the GaBi software [41]. The input considered 35\% content of food and kitchen waste, and a mixture of biodegradable garden and park waste. In addition, this system included a mechanical separation unit, for which energy is required for the selective collection fraction [42].

- The Ecoinvent database [40] was used for the AD modeling, containing substrates storage, fermentation in absence of oxygen (anaerobic), and the subsequent digestate storage. To generate $2.07 \mathrm{kWh}$ of energy, one cubic meter of biogas is considered [43].

- For the biodegradable portion of municipal solid waste, the thermal treatment collected from the GaBi database was assumed [41]. The modeling of a single portion involves energy generation and credits, attributed to the biodegradable fraction. The plant is composed of an incineration line that consists of a steam generator and a grate. The latter is used in $80 \%$ of the Spanish plants, becoming one of the most common 
technologies [44]. From one metric ton of waste, $1277 \mathrm{MJ}$ of steam is produced, $495 \mathrm{MJ}$ of energy, $220 \mathrm{~kg}$ of bottom ash, and $42 \mathrm{~kg}$ of slurries, filter cake, and boiler ash.

- The landfill model was based on the process for municipal household waste from the database of $\mathrm{GaBi}$ [41]. This system includes biogas recovery (with biogas and leachate management and deposition), diesel for the compactor, and sealing materials, for instance, mineral coating or clay. In agreement with the model, electricity is produced from $17 \%$ of the biogas through its collection, treatment, and burn. The $62 \%$ of the remaining gas is let out to the air, and the $21 \%$ is flared. A $50 / 50$ ratio of transpiration/runoff and a lifetime of 100 years were considered for the landfill, as well as a net energy production of $0.0942 \mathrm{MJ}$ per $\mathrm{kg}$ of municipal FLW [41].

Table 2. Percentage of FLW managed by treatment and region in 2015. Data represented in percentages calculated from mass balances in metric tons reported for each region. Regions: AN: Andalusia, AR: Aragon, AS: Principality of Asturias, BA: Balearic Islands, CAT: Catalonia, CL: Castile and Leon, CM: Castile-La Mancha, CN: Canary Islands, CT: Cantabria, EX: Extremadura, GA: Galicia, LR: La Rioja, MA: Community of Madrid, MU: Region of Murcia, NA: Chartered Community of Navarra, PV: Basque Country, VA: Valencian Community, SP: Spain.

\begin{tabular}{ccccc}
\hline Region & Landfill & Thermal treatment & AD & AC \\
\hline AN & $93.8 \%$ & & $2.3 \%$ & $3.9 \%$ \\
AR & $62.0 \%$ & & $3.0 \%$ & $7.9 \%$ \\
AS & $92.1 \%$ & $72.7 \%$ & $5.1 \%$ & $3.3 \%$ \\
BA & $18.9 \%$ & $18.4 \%$ & $15.7 \%$ & $16.5 \%$ \\
CAT & $49.4 \%$ & & $43.6 \%$ & \\
CL & $56.4 \%$ & & & \\
CM & $100.0 \%$ & & $4.3 \%$ & \\
CN & $95.7 \%$ & $64.9 \%$ & & \\
CT & $35.1 \%$ & & $14.9 \%$ & $0.9 \%$ \\
EX & $100.0 \%$ & $50.6 \%$ & $64.9 \%$ & \\
GA & $33.6 \%$ & & $25.5 \%$ & \\
LR & $35.1 \%$ & $10.6 \%$ & & \\
MA & $63.4 \%$ & & $26.6 \%$ & $12.1 \%$ \\
MU & $100.0 \%$ & & $6.7 \%$ & $2.1 \%$ \\
NA & $61.4 \%$ & $21.6 \%$ & $2.5 \%$ \\
PV & $65.9 \%$ & & $14.9 \%$ & $4.5 \%$ \\
VA & $75.9 \%$ & & &
\end{tabular}

The function of the system is to treat FLW; thus, all the treatments were compared in the same terms. However, all the management alternatives are multifunctional processes, adding an extra function to the system. Energy is recovered from AD, landfilling, and thermal treatment, which also produces steam. In the case of composting, material credits are obtained from the use of compost as fertilizer. In these multifunctional systems, the environmental burdens associated with a particular process must be partitioned over the various functional flows of that process [45]. To handle these processes, the ISO 14,044 proposes as a first solution to expand the system boundaries or divide the process into sub-processes [45]. In this case, the additional functions (generation of energy, steam, and compost) have been subtracted from the system in terms of production of electricity, or the generation of steam and fertilizer. To calculate the avoided burden for electricity, the TIAM-UCL model based on simulations of the electricity mix was considered. In 2040, according to the evolution of the BAU framework, approximately $60 \%$ of total power generation will come from coal, 20\% from hydropower, and almost 10\% from natural gas. In contrast, biomass and biomass with carbon capture sequestration, which will start to decline in 2025, will tend to disappear by 2040. Conversely, in 2040 if the evolution of a 2DS framework is considered, 55\% of the total electricity mix will come from nuclear, $20 \%$ from hydropower, and $10 \%$ from onshore wind. The decarbonization policies in the 
electricity sector could encourage the increase of nuclear power, which could lead to a debate on whether the outcome justifies any controversial strategy to achieve the Paris Agreement targets. This suggested another complementary and necessary policy vision together with climate policies. Finally, both scenarios (BAU and 2DS) suggested a decrease in biomass-generated power in 2025, which could disappear by 2040.

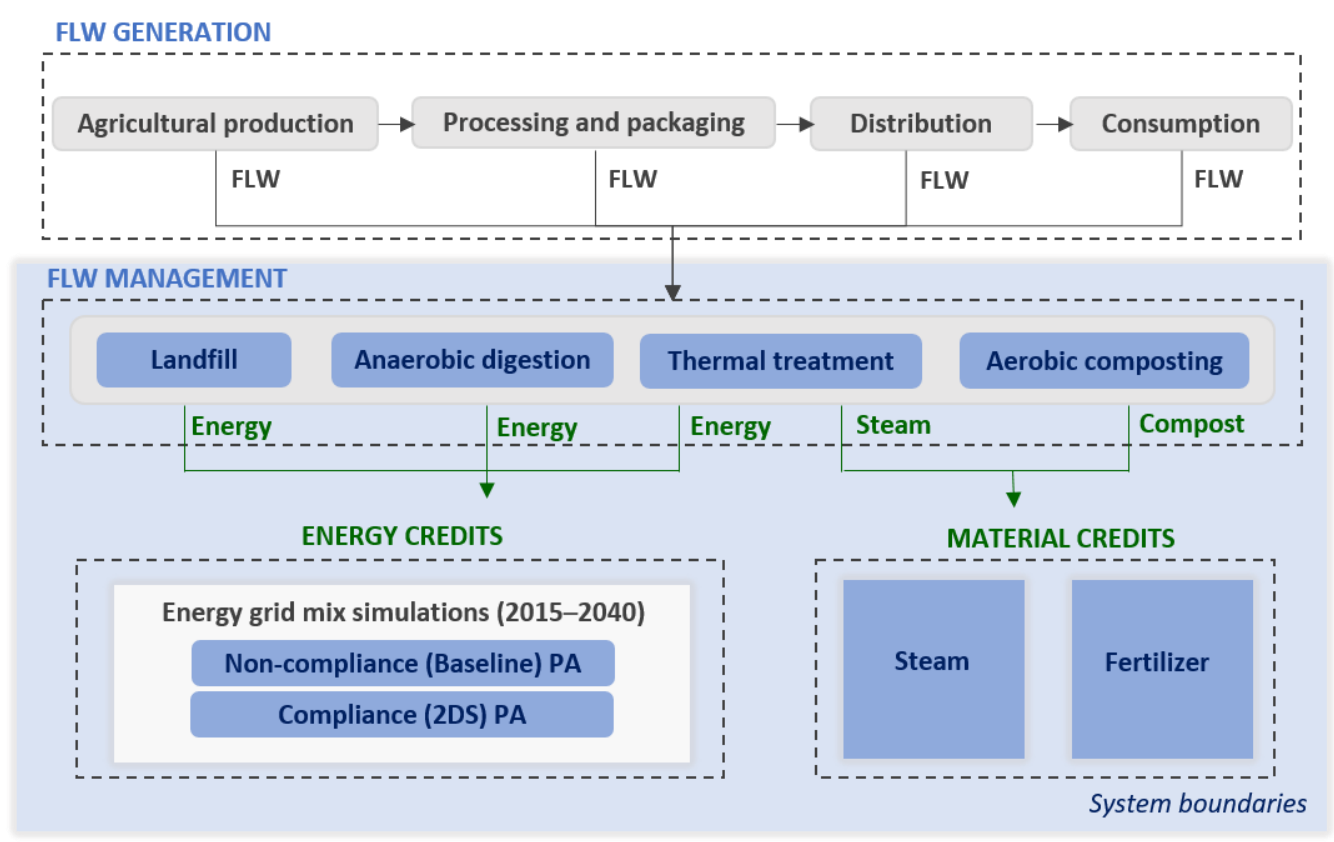

Figure 2. Graphical representation of the system boundaries and water footprint inventory of food loss and waste management strategies. PA: Paris Agreement targets.

Due to the construction of this model, the avoided loads from energy represent a reduction in the environmental impacts associated with the mix of each year. This implies that if the energy mix evolves towards cleaner energy sources, as in the 2DS situation, the avoided loads lose importance since the impacts generated are less. If the energy mix does not evolve towards cleaner energy sources (as in the BAU situation), the avoided loads have a greater effect.

These avoided burdens will have influence on the WF since there is clear link between energy and water consumption. According to Mesfin et al. [46], the WF for electricity and heat consumption is around 380 billion $\mathrm{m}^{3}$ per year, leading the water demand of biomass and hydropower.

\section{Life-Cycle Inventory}

A series of hypotheses and calculations were necessary so as to perform the life cycle inventory (LCI) of waste generation and management in each region for the stages of the food supply chain and the 11 categories of FLW. It was supposed that $49 \%$ of the total waste reported corresponds to FLW [34]. In order to decide the percentage of livestock production, agricultural production, and existing industries in each region, the assumed FLW percentage (49\%) was applied to a series of data collected by the Spanish Ministry of Agriculture, Fisheries, and Food [47,48]. Thereby, FLW generation in the agricultural production and processing and packaging stages was calculated for each region. Regarding the distribution and household stages, the percentage of FLW assumed was implemented in the population in 2015 [49], considering tourists as a part of the population in each area [50]. In order to calculate the fractions of FLW going to each of the four different management options considered, data from MITECO (Ministry of the Ecological Transition and the Demographic Challenge in Spain) [29], as well as from the CONAMA [34], were 
used. The same percentage of considered FLW (49\%) was considered from the total waste generation data.

\subsection{Water Footprint Profile}

A WF assessment can be represented by the WF indicator or by the WF profile. The former is related to one single impact category, that is water scarcity. On the other hand, according to the ISO 14,046 [10], the WF profile includes the water scarcity footprint (i.e., impacts related to freshwater consumption) and water degradation footprint (i.e., impacts due to freshwater and marine water degradation). The current study determined the WF profile of FLW management, evaluating firstly the water scarcity footprint using the AWARE method [11]. This method develops scarcity indicators that are used as midpoint characterization factors (CFs) for water consumption in life cycle impact assessment. AWARE CFs determine the water availability minus the demand of humans and environmental water requirements. CFs in AWARE range from 0.1 to 100 depending on regional watershed conditions in different parts of the world, or average national values. In this study, the input and output water flows were regionalized to the Spanish situation. In contrast, according to Boulay et al. [11] impacts due to freshwater degradation were assessed through the freshwater (FE) and marine eutrophication (ME) impact categories from the ReCiPe method [51]. In order to compare the scenarios, a weighting process was performed by considering the same importance of each of the factors. Table 3 shows the WF profile for the FLW management options, and Figure 3 presents the changes in the energy mix from 2015 to 2040 according to the BAU and 2DS frameworks.

Table 3. WF profile of the four management options considered in the study.

\begin{tabular}{|c|c|c|c|c|c|c|}
\hline \multirow[b]{2}{*}{ Impact Category } & \multirow[b]{2}{*}{ Landfill } & \multicolumn{2}{|c|}{ Thermal Treatment } & \multirow[b]{2}{*}{ AD } & \multicolumn{2}{|c|}{ AC } \\
\hline & & Incineration & Process Steam & & Composting & $\begin{array}{c}\text { Ammonium } \\
\text { Sulphate }\end{array}$ \\
\hline Freshwater Eutrophication (kg P eq.) & $3.00 \times 10^{-3}$ & $6.25 \times 10^{-6}$ & $-2.02 \times 10^{-6}$ & $2.00 \times 10^{-4}$ & $4.75 \times 10^{-5}$ & $-5.78 \times 10^{-5}$ \\
\hline Marine Eutrophication (kg N eq.) & $7.70 \times 10^{-3}$ & $1.00 \times 10^{-3}$ & $-2.52 \times 10^{-5}$ & $1.76 \times 10^{-5}$ & $2.00 \times 10^{-4}$ & $-2.80 \times 10^{-3}$ \\
\hline AWARE ( $\mathrm{m}^{3}$ world eq.) & 3.14 & 254.41 & -13.40 & $9.15 \times 10^{-2}$ & 23.67 & 2.33 \\
\hline
\end{tabular}

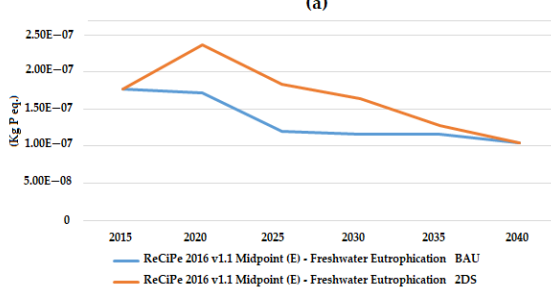

(b)

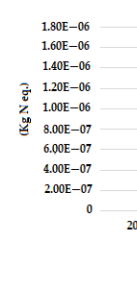

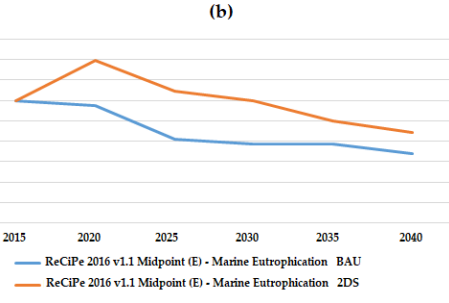

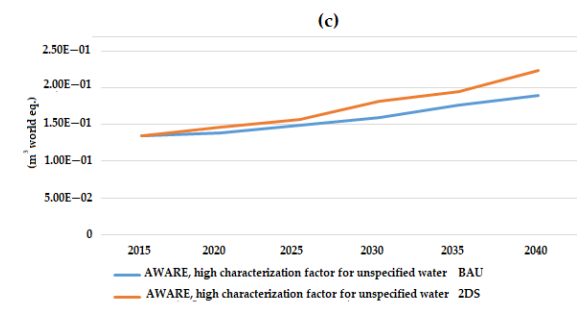

Figure 3. Evolution of the WF profile of the energy mixes in the BAU and 2DS situations, being (a) freshwater eutrophication (kg P eq.), (b) marine eutrophication (kg N eq.), and (c) AWARE ( $\mathrm{m}^{3}$ world eq.).

Negatives values were obtained in AWARE and ReCiPe indicators for the energy and material credits in incineration (steam and energy), landfilling (energy), AD (energy), and composting (fertilizer). Only for the AWARE method is the avoided burden of ammonium sulphate positive. In this method, CFs for water inputs (river, lake, and ground water requirements) are positive, with negatives for water outputs (emissions to fresh water). Thus, the AWARE indicator calculates the impact of the inputs less the outputs. This means that if the absolute value of indicator is positive, then the avoided burden is negative because it is considered as an environmental benefit. In the case of ammonium sulphate, the absolute value is negative and then the avoided burden is positive. This means that in this process, the impact linked to water emissions is higher than the impact from the water demand.

As represented in Figure 3, fresh and marine eutrophication show a similar trend for the energy mix, decreasing from 2015 to 2040 in the BAU and 2DS approximations. 
Biomass has the highest influence on the mix's impact ( $85 \%$ on average in marine and $95 \%$ in freshwater), which experienced a decrease of around $43 \%$ in both indicators for 2040 . However, the indicators raised in 2020 for the 2DS situation due to an increase of $35 \%$ in the biomass impact. On the other hand, for the AWARE method, the amount of water in the energy mix increased with the time. Hydropower energy represents more than $79 \%$ of the impact, which increased $72 \%$ in $2 \mathrm{DS}$ and $44 \%$ in the BAU situation.

\subsection{Limitations and Assumptions of the Study}

Due to the fact that the amount of FLW and the type of management of the different categories of FLW in the study is unknown, there is a major limitation in the analysis because the volume of FLW depends on factors such as time of year and region. Additionally, the lack of knowledge of FLW can lead to losses in the mass fraction, discrepancies with waste import and export flows, and unaccounted waste fractions. Furthermore, none of the existing information related to waste treatment and disposal methods is concerned with the generation of biowaste or FLW but rather with the generation of biodegradable municipal waste (biodegradable paper, cardboard, and textiles) [52]. These biodegradable wastes are often mixed with FLW in the further stages of FSC, which presents a great problem at the time of separating them. All these uncertainties and limitations make it more difficult to determine the percentage that applies only to FLW [53].

Furthermore, an attributional approach was applied in this study, as the electricity produced inside the system boundaries is sent to the national grid, and therefore the FW impacts of producing that amount of electricity are attributed to the system using the average electricity mix data. Another possible approach would be to consider within the system boundaries the marginal technology in the mix displaced by the energy produced. In this case, the system would be credited with the impacts of producing that amount of electricity using the displaced technology. Depending on the approach considered, the effects on the results will be different, and thus will be the conclusions drawn from the LCA for solid waste management systems [54]. Some technological developments related to waste management methods were not considered in this analysis, such as improved efficiency of electricity production or exhaust gas cleaning technology.

Since the evolution of FLW generation until 2040 was unknown, a logarithmic regression based on the projection of the World Bank Group [55] of Spanish population growth was used. In this way, a progressive and cumulative increase was assumed, reaching $6.7 \%$ in 2040 compared with 2015. As this increase did not generate changes in the scenario simulation, it was not considered in the methodology. Additionally, the SDG 12.3 target was not included in the modelled methodology, which aims to reduce food waste by half by 2030 , which was an important reason for the recent EU legislation, which established the requirement for EU member states to control food waste along the FSC as of 2020 [56].

From an impact assessment perspective, average AWARE CFs were used. Considering that water scarcity varies significantly between different areas of Spain, it could be argued that some regions of northern Spain could have been analyzed using specific spatially differentiated CFs, understanding the local availability of water resources, requirements for human consumption, economy, and ecosystem resilience and pressure.

\section{Results and Discussion}

\subsection{Water Scarcity Footprint}

The results of the different scenarios (S2-S6) do not improve regarding Scenario 1, as seen in Figure 4. Moreover, the water scarcity indicator did not vary or get a worst result in many of the regions and scenarios, highlighting the S6, where it suggested a zero influence in regard to the current situation. Nevertheless, Scenarios S4 and S5 are those that stand out for having the worst water scarcity footprint: S4 is dominated by thermal treatment, whereas in S5 one-third of the management is performed by thermal treatment. Therefore, it is evident that the worst management option in terms of water scarcity is thermal treatment. This can be explained due to the high quantity of water use for the 
steam process. In both $\mathrm{S} 4$ and S5, the regions that stand out as most affected by these supposed scenarios are Castile and Leon (CL), AN, and CM.

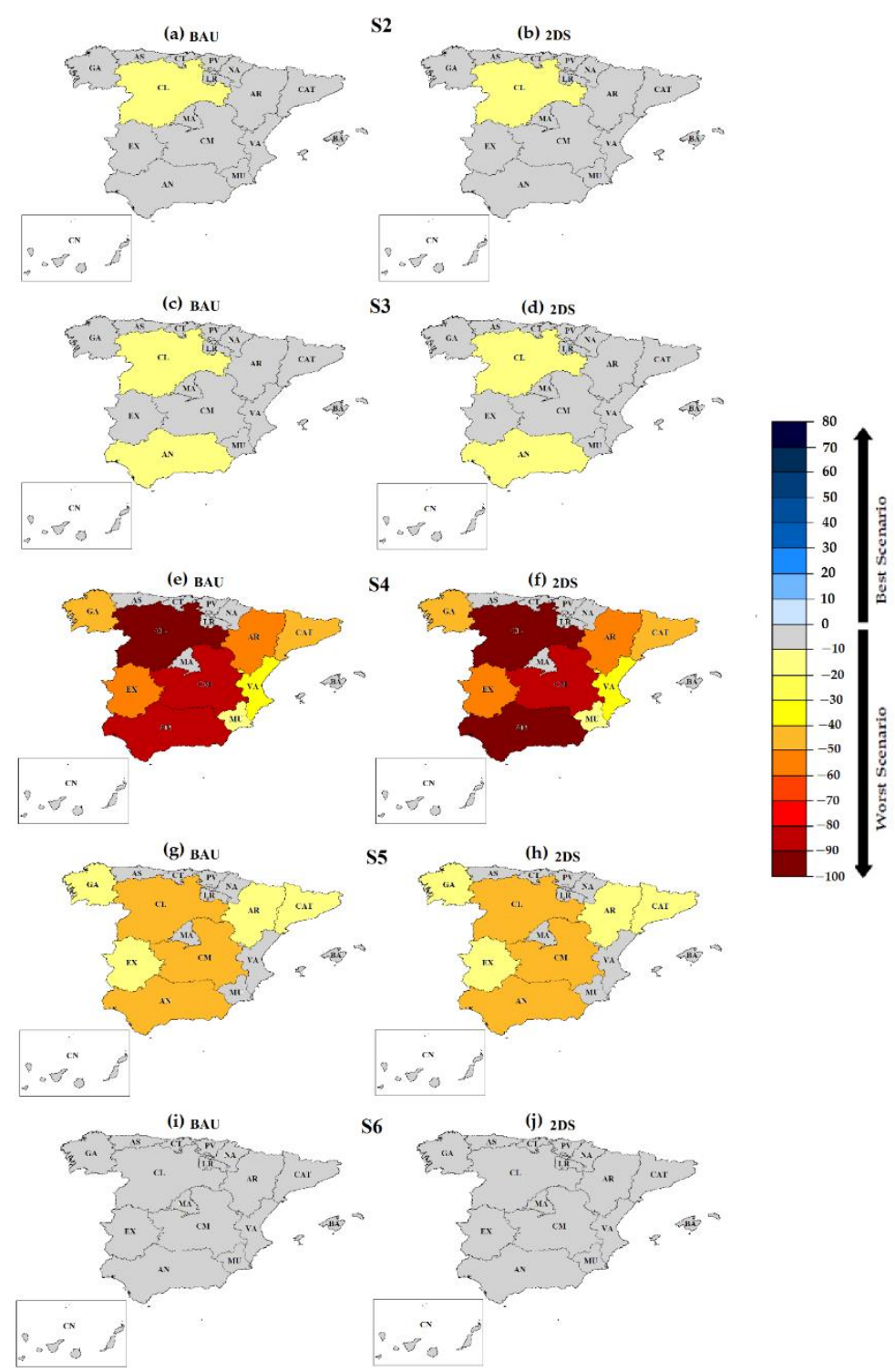

Figure 4. Comparison of the relative variation (\%) in water scarcity of the current scenario (S1) by region against the other FLW management scenarios considered. Scenario S2: (a) BAU and (b) 2DS; scenario S3: (c) BAU and (d) 2DS; scenario S4: (e) BAU and (f) 2DS; scenario S5: (g) BAU and (h) 2DS; scenario S6: (i) BAU and (j) 2DS.

Although in general the 2DS scenarios present slightly worse values, a difference is only seen in the case of AN, for which the 2DS situation would mean a worse water scarcity footprint in an S4 Scenario. This is due to the fact that the energy mixes are included as an avoided burden, in a context in which the rates of clean energy are higher. Thereby, the effect of the avoided burdens is lower in a 2DS framework, as there is less water scarcity generated through energy production. The results computed suggest that $\mathrm{S} 6$ is the bestperforming scenario, followed by S3 and S2. The only regions showing a slightly higher impact are CL and AN in the case of S3, and CL in the case of S2. This implies that a mixed scenario formed by $\mathrm{AD}$ and $\mathrm{AC}$ would be the most suitable option, followed by a scenario dominated by AD. 


\subsection{Water Degradation Footprint}

Figure 5 shows the results linked to the water degradation footprint for scenarios S2, S3, S4, S5, and S6 in the BAU and 2DS situation. Although, in general the 2DS scenarios had slightly worse values than BAU modelling, there is no significant difference between the two situations for scenarios S2, S4, S5, and S6. For S5, only the regions of CL and CM displayed a slightly worse performance in the 2DS situation. On the other hand, in S3 water degradation decreased for the 2DS approach in most of the regions, except for MU.
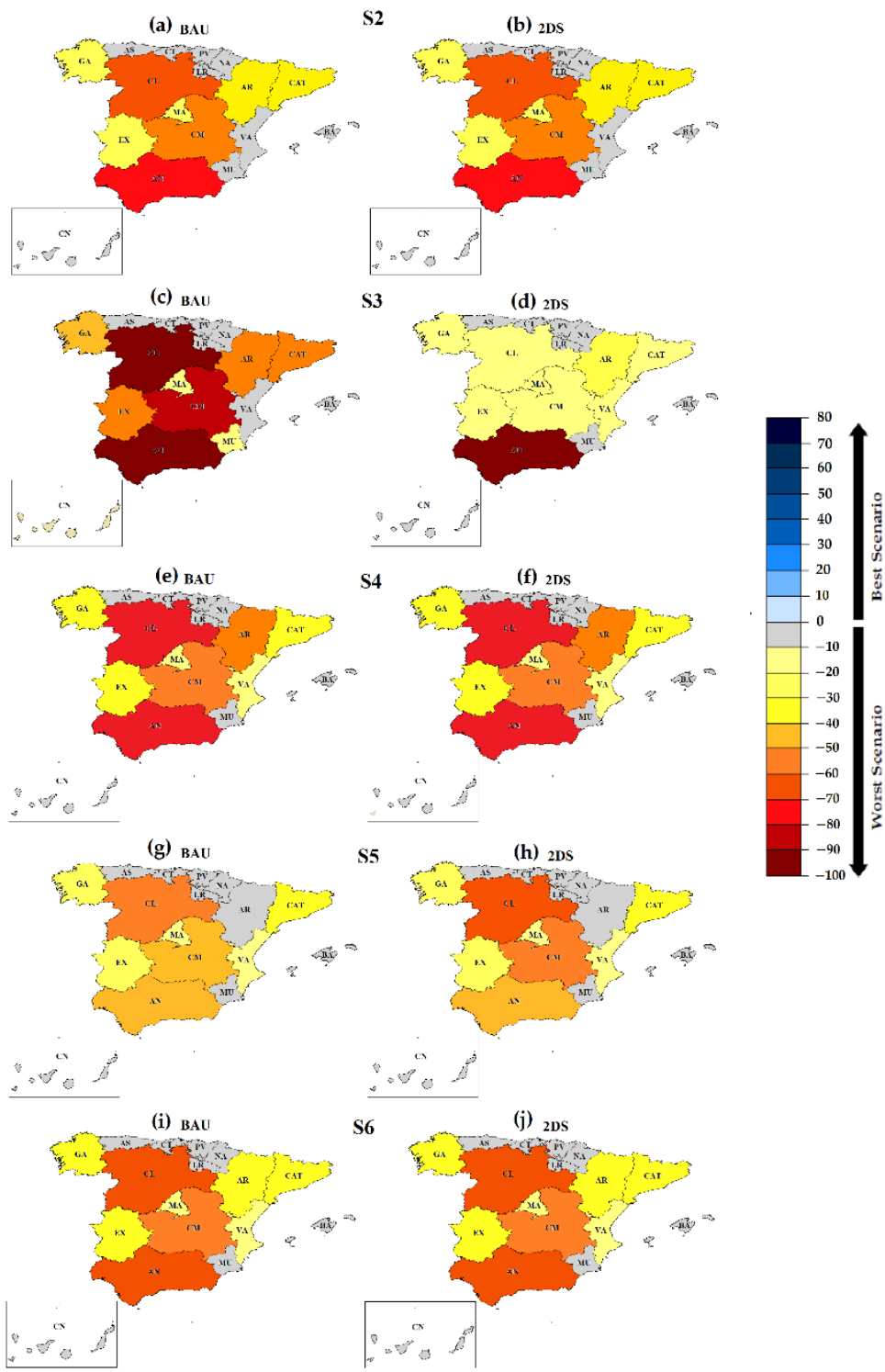

Figure 5. Comparison by region of the relative variation (\%) in water degradation of the current scenario (S1) versus the considered FLW management scenarios (a) BAU and (b) 2DS. scenario S3: (c) BAU and (d) 2DS; scenario S4: (e) BAU and (f) 2DS; scenario S5: (g) BAU and (h) 2DS; scenario S6: (i) BAU and (j) 2DS.

In general terms, in the BAU situation, $\mathrm{S} 3(75 \% \mathrm{AD}$ and $20 \% \mathrm{AC}$ ) showed the worst results, whereas in the 2DS approach, S4 (90\% incineration) provided the highest water degradation, the best option in that situation being S3. Thus, the evolution of the energy mix will influence the impact of $\mathrm{AD}$ and incineration technologies.

By regions, AN (94\% landfilling), CL (56\% landfilling and 44\% AD), and CM (100\% landfilling) had the greatest water degradation footprint, which is related to high landfilling rates. 
For AS (92\% landfilling and 8\% AC), CT (35\% landfilling and 65\% incineration), PV (66\% landfilling, 25\% incineration, 7\% AD, and 2\%AC), LR (35\% landfilling and 65\%), NA (61\% landfilling, 27\% AD, and 12\%AC), BA (19\% landfilling, 73\% incineration, 5\% AD, and $3 \% \mathrm{AC})$, and $\mathrm{CN}(96 \%$ landfilling and $4 \% \mathrm{AD})$ a similar result was obtained in the different scenarios for BAU and 2DS approaches. The regions in the north of Spain and the islands have the lowest water scarcity and degradation, being less influenced by the type of FLW management and with the compliance of the PA targets.

\subsection{Comparison with Previous Studies}

Results of a previous study by Hoehn et al. [30] highlighted how the incineration alternative worsens global warming in all studied regions in the BAU $(20 \%)$ and 2DS frameworks (between $60 \%$ and $80 \%$ ). These values coincide to a great extent with the results of the current study in terms of water scarcity and of water degradation in a 2DS framework. The rest of the scenarios show significant improvements compared with the current frameworks (BAU between 20\% and 60\% and 2DS between 20\% and 80\%). Moreover, the water scarcity reinforces the thesis of a better environmental performance in those frameworks that consider AD and, to a small extent, AC. The fact of highlighting AD and AC as FLW management options with a lower water consumption has also been cited in the literature in a study of Lundie and Peters [57], where home composting (10 1/FU) and centralized composting (19 1/FU) presented much less water consumption in comparison with co-disposal of FLW with municipal waste (2335 1/FU). In that research, anaerobic digestion was included in one of the two modalities of home composting. Moreover, they highlighted that centralized composting could be considered a temporary solution for educating households to separate biodegradable waste at the source before this fraction becomes anaerobically digested [57]. Sonesson et al. [58] also highlighted AD as an option presenting the lowest environmental impacts of all solid waste management systems, while composting offered environmental advantages compared with incineration methods. Additionally, Björklund et al. [59] concluded that large-scale centralized composting might increase environmental impacts relative to anaerobic digestion.

Therefore, AD and AC mixed systems appear to be the best option, i.e., the most environmentally sustainable. Therefore, this alternative was also considered as the most appropriate to fulfil the principles of the circular economy and the Sustainable Development Goals (SDG), especially with SDG6: to ensure availability and sustainable management of water and sanitation for all. In this general context, it is suggested that promotional strategies that encourage separate and selective collection at the source of FLW are needed. Finally, the comparison between BAU and 2DS presents important differences with the previous research, as previously there were significant differences, while in this work, a difference was only detected for the water scarcity footprint in S4 in the region of AN.

\section{Conclusions}

The results obtained highlight, in terms of water scarcity, frameworks that include AD and $\mathrm{AC}$ processes as those with the lowest environmental impact. In contrast, scenarios with thermal treatment presented the highest impacts. On the other hand, no significant variations between the BAU and 2DS situations were found, with the exception of the water scarcity footprint in AN if S4 is considered. Regarding water degradation, the evolution of the energy mix will influence the impact of AD and incineration technologies, with S3 being (75\% AD and 20\% AC) the worst option in BAU and the best option in 2DS, while S4 (90\% thermal treatment) was highlighted as the worst option in a 2DS framework.

However, many of the regions in the different scenarios of the WF profile do not improve or worsen the situation, with the water scarcity of S6 being especially remarkable, in which no region varies its results with regard to the current situation, neither in BAU nor in 2DS frameworks. In general, the regions in the north of Spain and the islands have the lowest water scarcity and degradation, being less influenced by the type of FLW management and with the compliance of the PA targets. 
Results aim to help the decision-making process in terms of future FLW management in Spain. Along this line, they confirm and reinforce the need to develop regionalized FLW management policies in Spain, moving from national to regional approaches when developing future roadmaps. This fact makes it evident that regional policies should be opted for, focusing primarily on regional plans and characteristics of FLW management systems, as opposed to national plans that seek uniformity of strategies.

Author Contributions: Conceptualization, D.H., M.M. and P.Q.; Data curation, R.A.; Formal analysis, D.H., M.M., J.L., I.R.-S., I.V.-R., R.A. and P.Q.; Funding acquisition, M.M. and R.A.; Investigation, D.H., M.M., J.L. and P.Q.; Methodology, D.H. and P.Q.; Project administration, R.A.; Supervision, P.Q.; Writing—original draft, D.H.; Writing—review \& editing, M.M., I.R.-S., I.V.-R., C.C., A.F.-R. and R.A. All authors have read and agreed to the published version of the manuscript.

Funding: This research was funded by the Spanish Ministry of Science and Competitiveness, grant number CERES-PROCON Project CTM2016-76176 (AEI/FEDER, UE) and KAIROS-BIOCIR Project PID2019-104925RB (AEO/FEDER, UE).

Acknowledgments: This study has been conducted thanks to the financial support of the Project Ceres-Procom: Food production and consumption strategies for climate change mitigation (CTM201676176-C2-1-R) (AEI/FEDER, UE), financed by the Ministry of Economy and Competitiveness of the Government of Spain. Daniel Hoehn thanks the Ministry of Economy and Competitiveness of the Spanish Government for their financial support via the research fellowship BES-2017-080296. Thanks are also due to the FCT/MCTES for the contracts granted to Paula Quinteiro (CEECIND/00143/2017) and for the financial support to CESAM (UIDB/50017/2020+UIDP/50017/2020) by means of national funds.

Conflicts of Interest: The authors declare no conflict of interest. The authors are responsible for the choice and presentation of information contained in this paper as well as for the opinions expressed therein, which are not necessarily those of UNESCO and which do not commit this organization.

\section{References}

1. Ridoutt, B.G.; Juliano, P.; Sanguansri, P.; Sellahewa, J. The water footprint of food waste: Case study of fresh mango in Australia. J. Clean. Prod. 2010, 18, 1714-1721. [CrossRef]

2. Shukla, P.R.; Skea, J.; Buendia, E.C.; Masson-Delmotte, V.; Pörtner, H.O.; Roberts, D.C.; Zhai, P.; Slade, R.; Connors, S.; van Diemen, R.; et al. (Eds.) Technical summary. In Climate Change and Land: An IPCC Special Report on Climate Change, Desertification, Land Degradation, Sustainable Land Management, Food Security, and Greenhouse Gas Fluxes in Terrestrial Ecosystems; IPCC: Geneva, Switzerland, 2019.

3. Aivazidou, E.; Tsolakis, N.; Iakovou, E.; Vlachos, D. The emerging role of water footprint in supply chain management: A critical literature synthesis and a hierarchical decision-making framework. J. Clean. Prod. 2016, 137, 1018-1037. [CrossRef]

4. Quinteiro, P.; Dias, A.C.; Pina, L.; Neto, B.; Ridoutt, B.G.; Arroja, L. Addressing the freshwater use of a Portuguese wine (“vino verde") using different LCA methods. J. Clean Prod. 2014, 68, 46-55. [CrossRef]

5. Hoekstra, A.Y.; Hung, P.Q. Virtual Water Trade: A Quantification of Virtual Water Flows between Nations in Relation to International Crop Trade; Value of Water Research Report Series No. 11; UNESCO-IHE: Delft, The Netherlands, 2002.

6. Chapagain, A.K.; Hoekstra, A.Y. Water Footprints of Nations; Value of Water Research Report Series No.16; UNESCO-IHE: Delft, The Netherlands, 2004.

7. Chapagain, A.K.; Hoekstra, A.Y.; Savenije, H.H.G.; Gautam, R. The water footprint of cotton consumption: An assessment of the impact of worldwide consumption of cotton products on the water resources in the cotton producing countries. Ecol. Econ. 2006, 60, 186-203. [CrossRef]

8. Hoekstra, A.Y.; Chapagain, A.K.; Aldaya, M.M.; Mekonnen, M.M. The Water Footprint Assessment Manual: Setting the Global Standard; Earthscan: London, UK, 2011.

9. Chapagain, A.; James, K. Accounting for the impact of food waste on water resources and climate change. In Food Industry Wastes; Elsevier: Amsterdam, The Netherlands, 2013; pp. 217-236.

10. ISO 14046, Environmental Management-Water Footprint_Principles, Requirements and Guidelines; International Organization for Standardization: Geneva, Switzerland, 2014.

11. Boulay, A.M.; Bare, J.; Benini, L.; Berger, M.; Lathuillière, M.J.; Manzardo, A.; Margni, M.; Motoshita, M.; Núñez, M.; Pastor, A.V.; et al. The WULCA consensus for water scarcity footprints: Assessing impacts of water consumption based on the available water remaining (AWARE). Int. J. LCA 2018, 23, 368-378. [CrossRef]

12. Bizarro, D.; Bunden, J.; Ciroth, A. AWARE, Regionalized LCIA in openLCA. 2018. Available online: https://www.openlca.org/ wp-content/uploads/2018/04/Documentation_AWARE_20180411.pdf (accessed on 19 February 2021). 
13. Blas, A.; Garrido, A.; Willaarts, B. Food consumption and waste in Spanish households: Water implications within and beyond national borders. Ecol. Indic. 2018, 89, 290-300. [CrossRef]

14. Caldeira, C.; Quinteiro, P.; Castanheira, E.; Boulay, A.M.; Dias, A.C.; Arroja, L.; Freire, F. Water footprint profile of crop-based vegetable oils and waste cooking oil: Comparing two water scarcity footprint methods. J. Clean Prod. 2018, 195, 1190-1202. [CrossRef]

15. Bong, P.X.H.; Malek, M.A.; Noor, Z.Z. A review on water footprint assessment and Water-Food-Energy Nexus for electronic and food products. Int. J. Eng. Technol. 2018, 7, 48. [CrossRef]

16. Mekonnen, M.M.; Gebens-Leenes, W. The Water Footprint of Global Food Production. Water 2020, 12, 2696. [CrossRef]

17. Ridoutt, B.G.; Eady, S.J.; Sellahewa, J.; Simons, L.; Bektash, R. Water footprinting at the product brand level: Case study and future challenges. Clean. Prod. 2009, 17, 1228-1235. [CrossRef]

18. Milà i Canals, L.; Chapagain, A.; Orr, S.; Chenoweth, J.; Anton, A.; Clift, R. Assessing freshwater use impacts in LCA, part 2: Case study of broccoli production in the UK and Spain. Int. J. Life Cycle Assess. 2010, 15, 598-607. [CrossRef]

19. Frischknecht, R.; Steiner, R.; Braunschweig, A.; Egli, N.; Hildesheimer, G. Swiss ecological scarcity method: The new version. In Proceedings of the 7th International Conference on EcoBalance, Tsukuba, Japan, 25-27 November 2006.

20. Kounina, A.; Margni, M.; Bayart, J.; Boulay, A.-M.; Berger, M.; Bulle, C.; Frischknecht, R.; Koehler, A.; Milà i Canals, L.; Motoshita, M.; et al. Review of methods addressing freshwater use in life cycle inventory and impact assessment. Int. J. Life Cycle Assess. 2013, 18, 707-721. [CrossRef]

21. WFN. Water Footprint-Product Gallery. Water Footprint Network. 2010. Available online: http://www.waterfootprint.org (accessed on 15 March 2021).

22. Karandish, F.; Hoekstra, A.Y.; Hogeboom, R.J. Reducing food waste and changing cropping patterns to reduce water consumption and pollution in cereal production in Iran. J. Hydrol. 2020, 586, 124881. [CrossRef]

23. López-Gunn, E.; Willaarts, B.; Dumont, A.; Niemeyer, I.; Martínez-Santos, P. The concept of water and food security in Spain. In Water, Agriculture and the Environment in Spain: Can We Square the Circle? CRC Press: Boca Raton, FL, USA, 2012 ; pp. $21-34$.

24. Duarte, R.; Pinilla, V.; Serrano, A. The water footprint of the Spanish agricultural sector: 1860-2010. Ecol. Econ. 2014, 108, 200-207. [CrossRef]

25. Villanueva-Rey, P.; Quinteiro PVázquez-Rowe, I.; Rafael, S.; Arroja, L.; Moreira, M.T.; Feijoo, G.; Dias, A.C. Assessing water footprint in a wine appellation: A case study for Ribeiro in Galicia, Spain. J. Clean. Prod. 2018, 172, 2097-2107. [CrossRef]

26. Vanham, D.; Hoekstra, A.Y.; Bidoglio, G. Potential water saving through changes in European diets. Environ. Int. 2013, 61, 45-56. [CrossRef]

27. Gustavsson, J.; Cederberg, C.; Sonesson, U.; Van Otterdijk, R.; Meybeck, A. Global Food Losses and Food Waste; Extent, Causes and Prevention. 2011. Available online: http://www.fao.org/sustainable-food-valuechains/library/detalles/es/c/266053/ (accessed on 19 November 2020).

28. Zero Waste Scotland. The Water and Carbon Footprint of Household Food and Drink Waste in the UK: A Summary for Scotland. 2011. Available online: https://www.wrap.org.uk/sites / files/wrap/Water_and_Carbon_Footprint_Report_Scottish_Summary. pdf (accessed on 19 November 2020).

29. Spanish Ministry for the Ecological Transition and the Demographic Challenge (MITECO). PEMAR, Plan Estatal Marco de Gestión de Residuos (2016-2022). 2015. Available online: https:/ /www.miteco.gob.es/es/calidad-y-evaluacion-ambiental/ planes-y-estrategias / pemaraprobado6noviembrecondae_tcm30-170428.pdf (accessed on 19 November 2020). (In Spanish).

30. Hoehn, D.; Laso, J.; Cristóbal, J.; Ruiz-Salmón, I.; Butnar, I.; Borrion, A.; Bala, A.; Fullana-i-Palmer, P.; Vázquez-Rowe, I.; Aldaco, R.; et al. Regionalized strategies for food loss and waste management in Spain under a life cycle thinking approach. Foods 2020, 9, 1765. [CrossRef] [PubMed]

31. Anandarajah, G.; Pye, S.; Ushner, W.; Kesicki, F.; Mcglade, C. TIAM-UCL Global Model Documentation, Working Paper, REF UKERC/WP7ESY/2011/001; University College of London: London, UK, 2011.

32. FAO. Definitional Framework of Food Loss, Working Paper. 2014. Available online: http://www.fao.org/fileadmin/user_ upload/save-food/PDF/FLW_Definition_and_Scope_2014.pdf (accessed on 19 November 2020).

33. Garcia-Herrero, I.; Hoehn, D.; Margallo, M.; Laso, J.; Bala, A.; Batle-Bayer, L.; Fullana, P.; Vazquez-Rowe, I.; Gonzalez, M.J.; Durá, M.J.; et al. On the estimation of potential food waste reduction to support sustainable production and consumption policies. Food Policy 2018, 80, 24-38. [CrossRef]

34. CONAMA. Congreso Nacional del Medio Ambiente, Estudio de la Situación Actual de las Plantas de Tratamiento MecánicoBiológico en España. 2014. Available online: http:/ / www.conama.org/conama/download/files/conama2014/CT\%202014/189 6711843.pdf (accessed on 19 November 2020). (In Spanish).

35. Deutsches Biomasserforschungzentrum. Anlagebestand Biogas und Biomethan-Biogaserzeugung und-Nutzung in Deutschland, 30. 2017. Available online: https://www.dbfz.de/fileadmin/user_upload/Referenzen/DBFZ_Reports/DBFZ_Report_30 .pdf (accessed on 19 November 2020). (In German).

36. Bang-Jensen, M.; Moller, J.; Scheutz, C. Comparison of the organic waste management systems in the Danish-German border region using life cycle assessment (LCA). Waste Manag. 2016, 49, 491-504. [CrossRef]

37. Vision 2020: UK Roadmap to Zero Food Waste to Landfill. 2013. Available online: https://storage.googleapis.com/www. bioregional.com/downloads/Vision-2020-UK-roadmap-to-zerofood-waste-to-landfill_Vision-2020_2013.pdf (accessed on 19 November 2020). 
38. Instituto para la Diversificación y Ahorro de la Energía. Borrador del Plan Nacional Integrado de Energía y Clima 2021-2030. Available online: https:/ / ec.europa.eu/energy/sites/ener/files/documents/spain_draftnecp.pdf (accessed on 17 November 2020). (In Spanish).

39. EC. European Commission, Council Directive 1999/31/EC. 1999. Available online: https://eur-lex.europa.eu/legal-content/ EN/TXT/PDF/?uri=CELEX:31999L0031\&from=EN (accessed on 19 November 2020).

40. Ecoinvent. Ecoinvent v3 Database, Ecoinvdent Centre. 2016. Available online: http://www.ecoinvent.org/ (accessed on 19 November 2020).

41. GaBi 9.2: Software-System and Databases for Life Cycle Engineering; Sphera: Stuttgart-Echterdingen, Germany, 2019.

42. Cimpan, C.; Wenzel, H. Energy implications of mechanical and mechanical-biological treatment compared to direct waste-toenergy. Waste Manag. 2013, 33, 1648-1658. [CrossRef]

43. Junta de Andalucía. 2011. Available online: https://www.agenciaandaluzadelaenergia.es/sites/default/files/documentos/ estudio_basico_del_biogas_0.pdf (accessed on 19 November 2020).

44. Margallo, M.; Aldaco, R.; Irabien, A.; Carrillo, V.; Fischer, M.; Bala, A.; Fullana, P. Life cycle assessment modelling of waste-toenergy incineration in Spain and Portugal. Waste Manag. Res. 2014, 32, 492-499. [CrossRef] [PubMed]

45. ISO 14044: Environmental Management-Life Cycle Assessment-Requirements and Management; International Standards Organization: Geneva, Switzerland, 2006.

46. Mekonnen, M.M.; Gerbens-Leenes, P.W.; Hoekstra, A.Y. The consumptive water footprint of electricity and heat: A global assessment. Environ. Sci. Water Res. Technol. 2015, 1, 285-297. [CrossRef]

47. Spanish Ministry of Agriculture, Fisheries and Food (MAPA). Encuesta sobre Superficies y Rendimientos de Cultivos. 2019. Available online: https:/ / www.mapa.gob.es/es/estadistica/temas/estadisticas-agrarias/boletin2019_tcm30-536911.pdf (accessed on 19 November 2020). (In Spanish).

48. Spanish Ministry of Agriculture, Fisheries and Food (MAPA). Informe Anual Industria (2015-2016). 2017. Available online: https://www.mapa.gob.es/es/alimentacion/temas/industria-agroalimentaria/_informeanualindustria2015-2016_ok_ tcm30-380020.pdf (accessed on 19 November 2020). (In Spanish).

49. Instituto Nacional de Estadística. Población por Comunidades Autónomas. 2015. Available online: https://www.ine.es/jaxiT3 /Tabla.htm?t=2915\&L=0 (accessed on 19 November 2020). (In Spanish).

50. Instituto Nacional de Estadística. Estadística de Movimientos Turísticos en Fronteras (FRONTUR). 2016. Available online: https:/ / ine.es/daco/daco42/ frontur/frontur1215.pdf (accessed on 19 November 2020). (In Spanish).

51. Goedkoop, M.J.; Heijungs, R.; Huijbregts, M.; De Schryver, A.; Struijs, J.; Van Zelm, R. ReCiPe 2008—A Life Cycle Impact Assessment Method Which Comprises Harmonised Category Indicators at the Midpoint and the Endpoint Level, 1st ed.; Report I: Characterisation; National Institute for Public Health and the Environment: Research Triangle Park, NC, USA, 2009.

52. Arcadis Project Number-11/004759, Version C, Assessment of the Options to Improve the Management of Biowaste in the European Union-Final Report, European Commission DG Environment. 2010. Available online: https://ec.europa.eu/ environment/waste/compost/pdf/ia_biowaste\%20-\%20final\%20report.pdf (accessed on 19 November 2020).

53. Vázquez-Rowe, I.; Ziegler-Rodríguez, K.; Margallo, M.; Kahhat, R.; Aldaco, R. Climate action and food security: Strategies to reduce GHG emissions from food loss and waste in emerging economies. Resour. Conserv. Recycl. 2021, 170, 105562. [CrossRef]

54. Bernstad Saraiva, A.; Souza, R.G.; Valle, R.A.B. Comparative lifecycle assessment of alternatives for waste management in Rio de Janeiro-Investigating the influence of an attributional or consequential approach. Waste Manag. 2017, 68, 701-710. [CrossRef] [PubMed]

55. World Bank Group. What aWaste 2.0, A Global Snapshot of Solid Waste Management to 2050. 2018. Available online: https: / / openknowledge.worldbank.org/handle/10986/30317 (accessed on 19 November 2020).

56. European Commission. Commission Delegated Decision (EU) 2019/1597. 2019. Available online: https:/ / eur-lex.europa.eu/ legal-content/EN/TXT/PDF/?uri=CELEX:32019D1597\&from=GA (accessed on 19 November 2020).

57. Lundie, S.; Peters, G.M. Life cycle assessment of food waste management options. J. Clean. Prod. 2005, 13, 275-286. [CrossRef]

58. Sonesson, B.; Björklund, A.; Carlsson, M.; Dalermo, M. Environmental and economic analysis of management systems for biodegradable waste. Resour. Conserv. Recycl. 2000, 28, 29-53. [CrossRef]

59. Björklund, A.; Dalermo, M.; Sonesson, U. Evaluating a municipal waste management plan using OWARE. J. Clean. Prod. 1999, 7 , 271-280. [CrossRef] 